www.jmscr.igmpublication.org

Impact Factor (SJIF): 6.379

Index Copernicus Value: 71.58

ISSN (e)-2347-176x ISSN (p) 2455-0450

crossref DOI: https://dx.doi.org/10.18535/jmscr/v6i6.40

Journal Of Medical Science And Clinical Research

IGM Publication

An Official Publication of IGM Publication

\title{
Three-Dimensional Magnetic Resonance Angiographic Evaluation of Circle of Willis and Its Anatomical Variations in General Population
}

Authors

\author{
Dr Rana Kirti ${ }^{1}$, Dr Sunia Indrajeet Singh $^{2}$, Dr Gehlot Ramanand ${ }^{3}$ \\ Dr Chauhan Ajay Singh* ${ }^{4}$, Dr Kumar Ramesh ${ }^{5}$ \\ ${ }^{1}$ Professor, ${ }^{2,4,5}$ Resident, ${ }^{3}$ Professor and Head
}

Department of Radiology, Dr. SN Medical College, Jodhpur, Rajasthan, India

Email: inderjeetsunia@gmail.com,drkirtichaturvedy@gmail.com,dr.ramanandgehlot@gmail.com

\begin{abstract}
Background: Circle of Willis is the most important collateral circulation system in brain. Primary goal of imaging is to find out its integrity and hypoplastic for explaining the predisposition / cause of stroke and prior to vascular surgeries and interventional procedures.
\end{abstract}

Aims \& Objectives: To evaluate \& describe various patterns of anatomical variations of circle of Willis, elaborate its clinical significance and determine average vessels diameters in general Indian population by using 3D time-of-flight MR angiography.

Methodology: A cross sectional prospective study was undertaken on 200 patients on Philips $1.5 T$ Achieva MR scanner using non-contrast 3DTOF transaxial acquisition. Images were reviewed on the Philips Intellispaceportal workstation.

Results: The prevalence of complete configuration of the circle was 9\%. There was significantly higher incidence of complete circle in $<40 y r$ age group (24\%) than >40yr age group (4\%) ( $p<0.0001)$. An incomplete circle was noted in $91 \%$ subjects (60\% males and $40 \%$ females). Anterior circulation was complete in $44 \%$ and incomplete in $56 \%$ whereas posterior circulation was complete in $14 \%$ and incomplete in $86 \%$. Posterior circle variations were significantly higher than anterior circle $(p<0.0001)$. Average vessel diameters were slightly higher in male population. Also, average diameters were observed to be greater in anterior circle in below 60 age group and in above 60 age group posterior circle diameters were larger.

Conclusion: In today's scenario, the role of $3 D$ TOF MR angiography in preoperative evaluation of patients undergoing brain, ICA \& aortic arch surgeries and advanced interventional procedures cannot be underestimated in order to avoid life-threatening complications.

Keywords: Magnetic Resonance Angiography, 3D TOF MRA, Circle of Willis, Anatomical Variations, Stroke, Impact.

\section{Introduction}

Circle of Willis (CoW) is a confluence of flow from three vessels: both internal carotid arteries and the basilar artery around the optic chiasm and infundibulum of the pituitary stalk in the suprasellar cistern. Therefore, the hemodynamics in the CoW is anatomically significantly different from the hemodynamics in normal branching 
situations ${ }^{1}$. As a collateral circulation, it plays a pivotal role in the pathophysiology of cerebral ischemia. Persistence or absence of these protective vascular pathways may determine the severity of ischemic injury. Due to its large variations, diverse consequences of clinical disease prognoses are obtained. A pre-operative examination of the structure and variations of the Circle will help in assessment and planning of neurological complications and associated secondary risks of morbidity and mortality.

\section{Methods}

A cross sectional prospective study was undertaken in the Department of Radiodiagnosis of Dr. S. N. Medical College, Rajasthan. A total of 200 subjects with no manifestations of cerebrovascular diseases were analyzed on Philips 1.5T Achieva MR scanner using Philips intellispace portal workstation. The MR angiography protocol consisted of non-contrast 3DTOF transaxial acquisition. The scanning sequences applied on MRI were DWI, and GR/T2*WI. MRA was adopted using the 3D-TOF MRA in axial plane with the following parameters: TR $25 \mathrm{~m} / \mathrm{s}$, TE $6.9 \mathrm{~ms}$, Relative SNR 1.00 , NSA 1 , FOV $20 \mathrm{~cm} \times 20 \mathrm{~cm} \mathrm{x} 12.6 \mathrm{~cm}$, matrix $495 \times 284 \times 180$ and slice thickness $0 \mathrm{~mm}$. 180 images were obtained. Images were analyzed using MIP and volume rendering on the Philips Intellispaceportal workstation.12 subjects were excluded from study because of incidentally detected old infarcts, arteriovenous malformation or brain tumor.

Vessel size $<1 \mathrm{~mm}$ were considered hypoplastic. Any vessel segment continuously visualized in whole length with diameter $>1 \mathrm{~mm}$ and showing normal flow related enhancement was considered normal. Any vessel segment which was not visualized in its expected course was considered as aplastic/absent. Circle of Willis was considered complete when the classical polygonal form is visualized and incomplete when there is absence/ hypoplasia of any of the vessels constituting the Circle.
Anterior circulation includes bilateral internal carotid arteries (ICA), bilateral anterior cerebral arteries (ACAs) and anterior communicating artery (ACOM).

Posterior circulation includes basilar artery, bilateral posterior cerebral arteries (PCAs) and bilateral posterior communicating arteries (PCOM).

As per Hagen-Poiseuille equation for laminar flow, role of hypoplastic vessels as collateral during acute obstruction is insignificant and a hypoplastic vessel is as good as absent as far as collateralization is concerned.

Anterior circulation was considered as codominant when both A1 segments of ACA are of comparable size. Unilateral dominant A1 segment was considered when contralateral A1 segment was hypoplastic or aplastic.

A partial fetal configuration is when diameter of P1 is smaller than PCOM. Pure fetal is said when P1 segment is absent and PCA is formed by extension of PCOM.

Maximum diameter of each vessel forming the circle was measured using the Philips intellispace software using source images in axial plane.

Data was analyzed in Microsoft excel worksheet 2016 and mean, standard deviation and standard error of mean were calculated.

Statistical Analysis: The chi square test, two sample $\mathrm{Z}$ test and unpaired $\mathrm{t}$ test were performed in SPSS version 20, with statistical significance evaluated at the 0.05 alpha level.

\section{Results}

A total of 188 cases were analyzed for variation patterns in anterior and posterior parts of circle of Willis and diameters of vessels. 
Table 1: Circle of Willis integrity in male and female population $(n=188)$

\begin{tabular}{|l|c|c|c|c|c|c|}
\hline CIRCLE OF WILLIS & \multicolumn{2}{|c|}{$\begin{array}{c}\text { TOTAL } \\
(\mathbf{n = 1 8 8})\end{array}$} & \multicolumn{2}{c|}{$\begin{array}{c}\text { MALE } \\
(\mathbf{n = 1 1 3})\end{array}$} & \multicolumn{2}{c|}{$\begin{array}{c}\text { FEMALE } \\
(\mathbf{n = 7 5})\end{array}$} \\
\hline COMPLETE & 16 & $9 \%$ & 10 & $9 \%$ & 6 & $8 \%$ \\
\hline INCOMPLETE & 172 & $91 \%$ & 103 & $91 \%$ & 69 & $92 \%$ \\
\hline TOTAL & 188 & $100 \%$ & 113 & $60 \%$ & 75 & $40 \%$ \\
\hline EXCLUDED & \multicolumn{2}{|c|}{12} & \multicolumn{2}{c|}{6} & \multicolumn{2}{c|}{6} \\
\hline GRAND TOTAL & \multicolumn{2}{|c|}{200} & \multicolumn{2}{c|}{119} & \multicolumn{2}{c|}{81} \\
\hline
\end{tabular}

p-value is 0.856344 .

Circle of Willis was complete in $9 \%$ individuals and incomplete in rest of $91 \%$ individual. The result shows that no significant difference in circle

Table 2: Contingency table for integrity of anterior and posterior circulation $(n=188)$

\begin{tabular}{|l|c|c|}
\hline & COMPLETE & INCOMPLETE \\
\hline ANTERIOR CIRCULATION & $83(44 \%)$ & $105(56 \%)$ \\
\hline POSTERIOR CIRCULATION & $26(14 \%)$ & $162(86 \%)$ \\
\hline
\end{tabular}

The p-value is $<.00001$.

Anterior circulation was incomplete in $56 \%$ and complete in $44 \%$ whereas posterior circulation was incomplete in $86 \%$ and complete in $14 \%$. The

of Willis configuration in male and female population.

Table 3: Contingency table for Circle of Willis integrity in below and above40yrs age group

\begin{tabular}{|l|c|c|}
\hline & Complete & Incomplete \\
\hline$<$ 40yr age group $(\mathbf{n = 4 1})$ & $10(24 \%)$ & $32(76 \%)$ \\
\hline$>$ 40yr age group $(\mathbf{n = 1 4 7})$ & $6(4 \%)$ & $139(96 \%)$ \\
\hline
\end{tabular}

The p-value is .00006.

The results showed that incompleteness of circle of Willis is significantly higher in above 40yr age group.

Following variation patterns were noted in anterior circulation
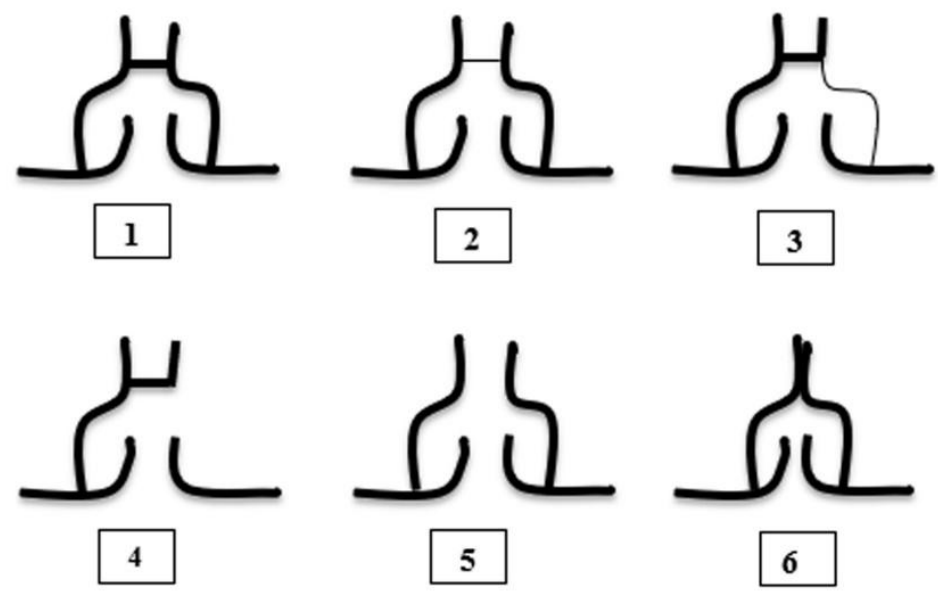

1. Classical type - normal bilateral A1

4. Absent unilateral A1 segment with normal anterior communicating artery (ACOM).

2. Hypoplastic ACOM with normal bilateral A1

3. Hypoplastic unilateral A1 with normal ACOM result shows that there are significantly higher variations in posterior circle than in anterior circle. 


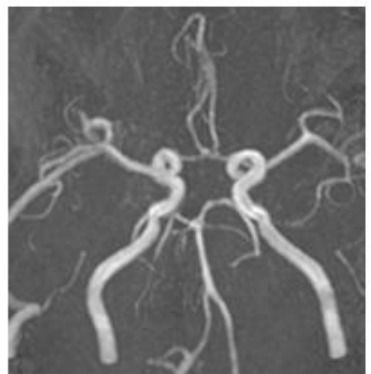

Type 1

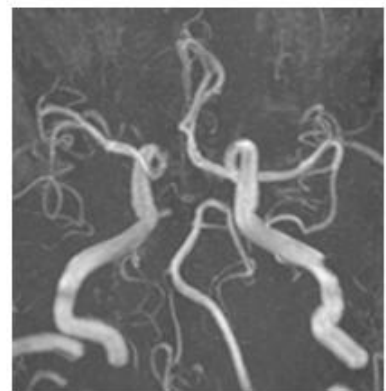

Type 4

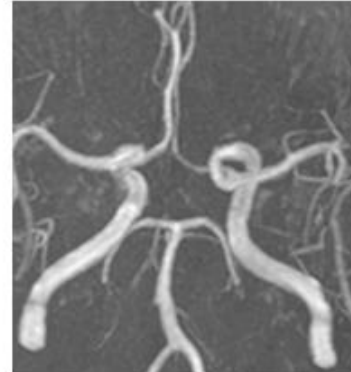

Type 2

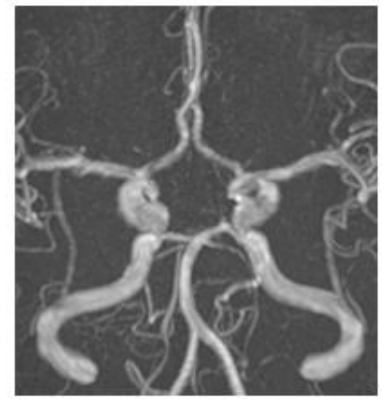

Type 5

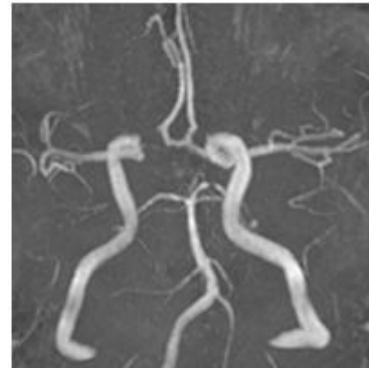

Type 3

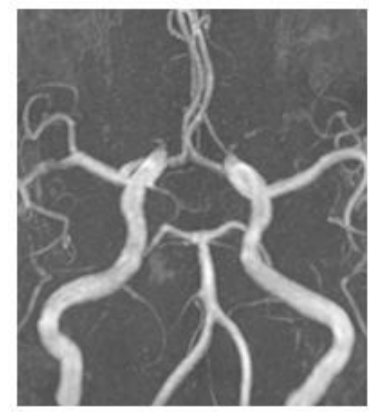

Type 6

Following variation patterns were noted in posterior circulation<smiles>CCC(C)[C@H](C(C)C)C1CCC1</smiles><smiles>CC[C@H](C)C(C)C</smiles>

$\mathrm{E}$<smiles>CCCC(C)C</smiles>

I

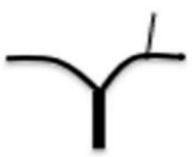

$\mathrm{M}$
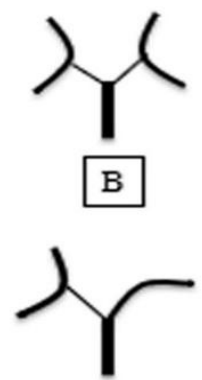

$\mathrm{F}$

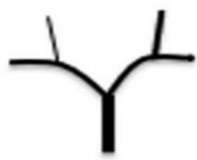

$\mathrm{J}$<smiles>CC(C)C(C)C(C)C</smiles>

N
A. Classical type, normal bilateral P1
C. Unilateral partial fetal type PCA segments with bilateral posterior
D. Absent bilateral PCOM communicating arteries (PCOM)
E. Absent unilateral PCOM
B. Bilateral partial fetal type posterior cerebral arteries with both P1 segments are
F. Absent unilateral PCOM with contralateral partial fetal type PCA patent 
G. Unilateral pure fetal type PCA withabsent contralateral PCOM

H. Unilateral pure fetal type PCA

I. Unilateral pure fetal type PCA \& contralateral partial fetal type

J. Hypoplastic unilateral PCOM
K. Bilateral pure fetal type PCA

L. Hypoplastic bilateral PCOM

M. Unilateral hypoplastic PCOM

N. Unilateral hypoplastic PCOM with contralateral partial FTP

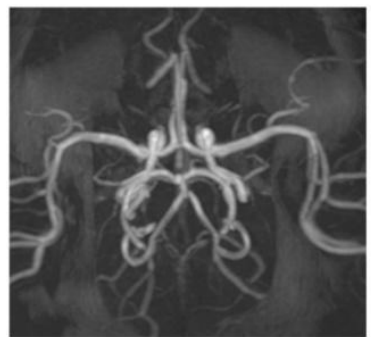

Type A

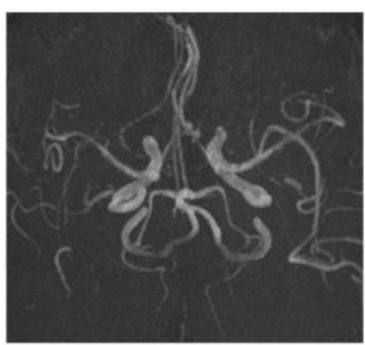

Type D

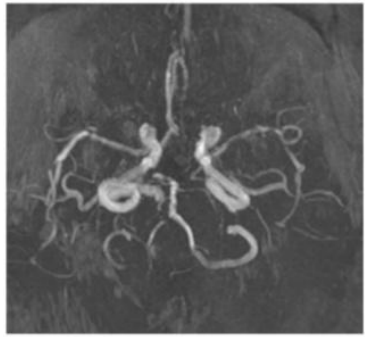

Type G

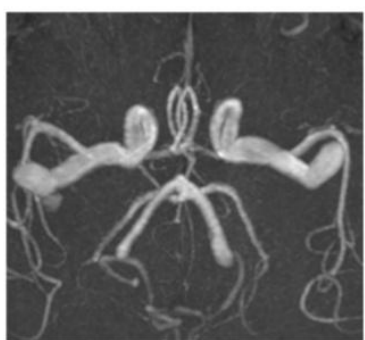

Type J

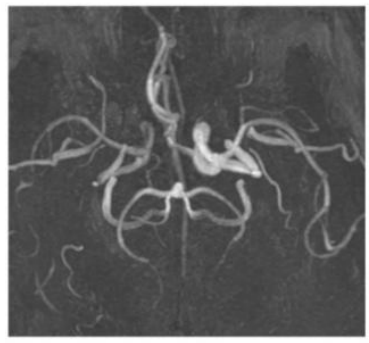

Type M

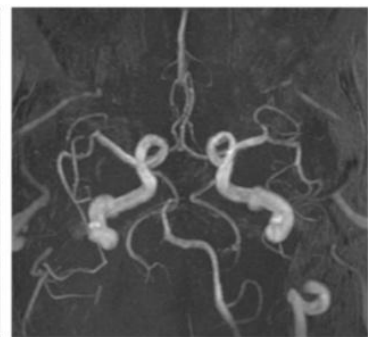

Type B

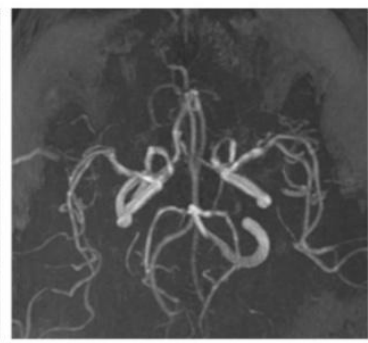

Type E

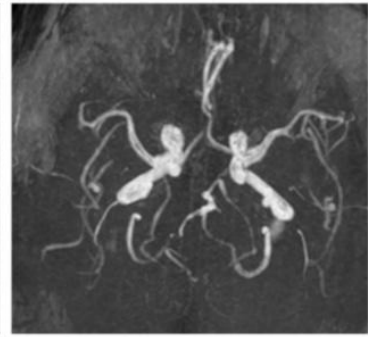

Type $\mathrm{H}$

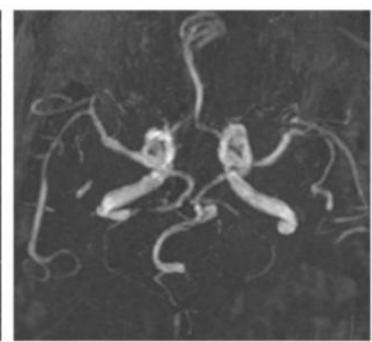

Type K

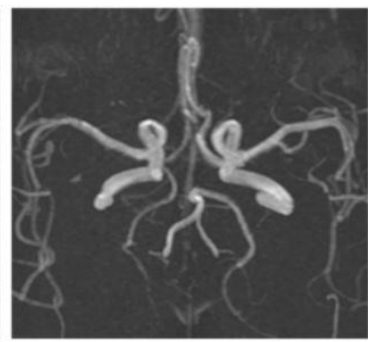

Type N

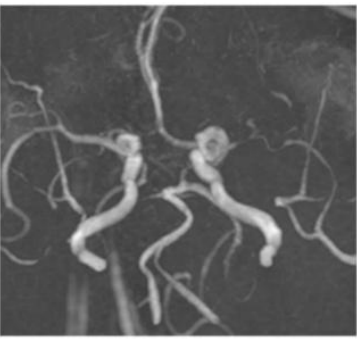

Type C

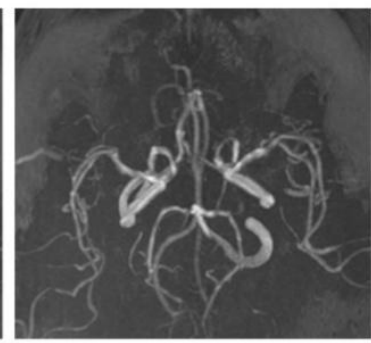

Type F

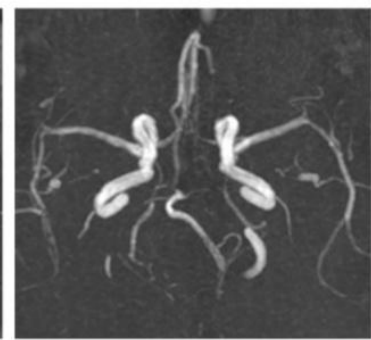

Type I

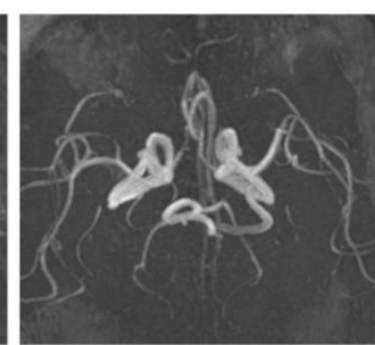

Type L 
Table 4 : Dominance of A1 segment $(n=188)$

\begin{tabular}{|l|c|c|}
\hline ACA Dominance & Number & Percentage \\
\hline Codominant & 168 & $89 \%$ \\
\hline Right dominant & 7 & $4 \%$ \\
\hline Left dominant & 13 & $7 \%$ \\
\hline
\end{tabular}

Most of the subjects (89\%) had a codominant type anterior circulation with slightly higher incidence of left dominant circulation in rest of the population. Right A1 is absent in 10 cases while left A1 in 3 cases. Similarly, right P1 is absent in 11 cases while left $\mathrm{P} 1$ in 9 cases indicating a dominant position of left development. PCOM absence is similar on right and left sides.

Table 5: Relation between anterior and posterior circle variations $(n=188)$

\begin{tabular}{|c|c|c|c|c|c|c|c|c|c|c|c|c|c|c|c|c|}
\hline Type & \multicolumn{6}{|c|}{ Integral posterior circulation } & \multicolumn{8}{|c|}{ Nonintegral posterior circulation } & Total & \%age \\
\hline \multirow[t]{2}{*}{ Integral anterior circle } & \multirow[b]{2}{*}{$\mathbf{A}$} & \multirow[b]{2}{*}{ B } & \multirow[b]{2}{*}{$\mathbf{C}$} & \multirow[b]{2}{*}{$\mathbf{J}$} & \multirow[b]{2}{*}{$\mathbf{L}$} & \multirow[b]{2}{*}{$\mathbf{N}$} & \multirow[b]{2}{*}{ D' } & \multirow[b]{2}{*}{$\mathbf{E}$} & \multirow[b]{2}{*}{$\mathbf{F}$} & \multirow[b]{2}{*}{$\mathbf{G}$} & \multirow[b]{2}{*}{$\mathbf{H}$} & \multirow[b]{2}{*}{ I } & \multirow[b]{2}{*}{$\mathbf{K}$} & \multirow[b]{2}{*}{$\mathbf{M}$} & & \\
\hline & & & & & & & & & & & & & & & & \\
\hline 1 & 16 & 2 & 2 & - & 3 & 2 & 38 & 14 & 4 & 2 & 2 & 2 & 1 & & & 47 \\
\hline 2(ACOM hypoplastic) & 4 & 1 & 3 & 2 & - & - & 17 & 7 & 2 & - & - & - & - & & 36 & 19 \\
\hline 3(A1 hypoplastic) & 1 & - & - & - & - & & 4 & - & 1 & - & - & - & - & & 6 & 3 \\
\hline \multicolumn{17}{|c|}{ Non-integral anterior circle } \\
\hline 4(A1 absent) & 1 & - & 2 & - & - & & 6 & 2 & - & 2 & 1 & 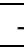 & 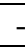 & 1 & 15 & 8 \\
\hline 5(ACOM absent) & 4 & 1 & - & - & - & & 8 & 2 & 1 & 1 & 4 & 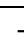 & 1 & & 22 & 12 \\
\hline 6 & 1 & 1 & - & 1 & - & & 8 & 7 & - & 2 & 1 & 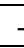 & - & & 21 & 11 \\
\hline Total & 27 & 5 & 7 & 3 & 3 & 2 & 81 & 32 & 8 & 7 & $\varepsilon$ & 2 & 2 & 1 & 188 & \\
\hline \%age & 14 & 3 & 4 & 1.5 & 1.5 & 1 & 43 & 17 & 5 & 4 & 5 & 1 & 1 & 0. & & \\
\hline
\end{tabular}

Most common configuration in anterior circulation was classic (complete) type (47\%). and rarest being type 3; hypoplastic unilateral A1 with patent contralateral A1 \& ACOM noted in 3\% of subjects. Most common posterior circulation configuration was type D; absent bilateral PCOM in $43 \%$ and rarest is type $\mathrm{M}$; unilateral hypoplastic PCOM with absent contralateral PCOM \& bilateral P1 patent. Most common type D configuration was frequently associated with type 1 i.e. classical complete anterior circle in $\sim 50 \%$ of subjects.

Since there is very high resistance in hypoplastic vessels according to Hagen-Poiseuille formula, above mentioned table can be condensed into following:

Table 6: Relation between anterior and posterior circle variations considering hypoplastic vessels as absent $(n=188)$

\begin{tabular}{|c|c|c|c|c|c|c|c|}
\hline \multirow[b]{2}{*}{$\begin{array}{l}\text { Anterior } \\
\text { circulation }\end{array}$} & \multicolumn{6}{|c|}{ Posterior circulation } & \multirow[b]{2}{*}{ Total } \\
\hline & $\begin{array}{l}\text { Type I } \\
\text { (A) }\end{array}$ & $\begin{array}{l}\text { Type II } \\
(\mathrm{B}, \mathrm{K}, \mathrm{I})\end{array}$ & $\begin{array}{c}\text { Type } \\
\text { III }(\mathrm{C}, \mathrm{H})\end{array}$ & $\begin{array}{l}\text { Type IV } \\
(\mathrm{D}, \mathrm{L}, \mathrm{M})\end{array}$ & $\begin{array}{c}\text { Type V } \\
(\mathrm{E}, \mathrm{J})\end{array}$ & $\begin{array}{c}\text { Type } \\
\text { VI }(F, G, N)\end{array}$ & \\
\hline Type 1 (classic) & $16(8.5 \%)$ & $5(3 \%)$ & $4(2 \%)$ & $41(22 \%)$ & $14(7.5 \%)$ & $8(4 \%)$ & $88(47 \%)$ \\
\hline Type $2(2,5,6)$ & $9(5 \%)$ & $4(2 \%)$ & $8(4 \%)$ & $33(17.5 \%)$ & $19(8.5 \%)$ & $6(3 \%)$ & $79(42 \%)$ \\
\hline Type $3(3,4)$ & $2(1 \%)$ & 0 & $3(1.5 \%)$ & $11(6 \%)$ & $2(1 \%)$ & $3(1.5 \%)$ & $21(11 \%)$ \\
\hline Total & $27(14 \%)$ & $9(5 \%)$ & $15(8 \%)$ & $85(45 \%)$ & $35(19 \%)$ & $17(9 \%)$ & 188 \\
\hline
\end{tabular}

Following inferences can be made from the above table :

1. $3 \%(n=5)$ had bilateral P1absent/ hypoplastic and complete anterior circulation. Therefore, bilateral ICA supply blood to anterior and posterior circulation. So, clamping/blockage of one ICA will cause infarction of ipsilateral MCA \& PCA territory without potential of collateral flow from contralateral ICA or ipsilateral PCA.
2. $2 \%(\mathrm{n}=4)$ had absent/hypoplastic ACOM with absent b/l P1 meaning thereby that right ICA supply entire right cerebral hemisphere and left ICA supply entire left hemisphere. So, clamping/blockage of one ICA will cause massive infarction of entire ipsilateral ACA, MCA \& PCA territory without potential of collateral flow from contralateral ICA or posterior circulation.

3. $17.5 \%(n=33)$ had absent ACOM \& bilateral PCOM. So, B/L PCA are supplied by basilar 
artery; right ICA supplies right ACA \& MCA \& left ICA supplies left ACA \& MCA. Hence, three independent non-communicating circulations exists. So, in case of right ICA block/clamping there will not be any circulation to supply right ACA \& MCA territory. Similarly, block/clamping of left ICA will result in large infarct in left ACA \& left MCA territory without potential for collateralization.

4. $8.5 \%(n=19)$ had absent unilateral PCOM and ACOM. In this configuration, one MCA/ACA territory supplied by ipsilateral ICA will be isolated while contralateral MCA, ACA \& b/l PCA territory will be interconnected. Hence, obstruction of one ICA will cause major infarct in ipsilateral MCA \& ACA territory without any potential for primary collateralization. Whereas if other ICA is blocked, circulation in MCA \& ACA territory will be supplied via posterior circulation and hence there will not be any infarct despite ICA occlusion.

5. $22 \%(n=41)$ had absent $b / 1$ PCOM and complete anterior circulation. Therefore, in case of block/clamping of one ICA will provide collaterals from contralateral ICA and hence there would be no risk of infarction.

6. $7.5 \%(n=14)$ had absent unilateral PCOM with complete anterior circulation. Therefore, either ICA can be clamped/blocked without risk of stroke.
7. If $\mathrm{ACOM}$ is absent and unilateral/bilateral $\mathrm{P} 1$ segment is hypoplastic then risk of stroke is present. If unilateral P1 is absent with absent ACOM $\{$ in our study $4 \% \quad(n=8)\}$ then clamping/blockage of ipsilateral ICA will cause major stroke in entire ipsilateral cerebral hemisphere. If bilateral $\mathrm{P} 1$ is also absent with absent ACOM then clamping of either ICA will cause stroke in ipsilateral cerebral hemisphere (ACA,MCA\& PCA territory). So, combination of ACOM absence and P1/PCOM absence will cause risk of stroke on ipsilateral ICA clamping. In our study, 3\% $(\mathrm{n}=70)$ had this type of circulation.

8. $3 \%(n=6)$ had absent unilateral PCOM with contralateral P1 absent and absent ACOM. In this situation, clamping of ICA on side of hypoplastic/absent P1 segment will cause major infarct in entire ACA, MCA \& PCA territory while blockage/clamping of ICA on side of absent PCOM will cause infarct in ACA \& MCA territory.

$8 \%$ individuals had hypoplastic vertebral artery on right while $8.5 \%$ had left vertebral artery hypoplastic. Number of hypoplasia/absence was similar on left and right in case of P1 i.e. 8.5\%. Meaning thereby, there is no effect of laterality on P1/VA hypoplasia. In our study, the overall frequency of vertebral artery hypoplasia was $16.5 \%$.

Table7: Contingency table for correlation between anterior and posterior circle integrity $(n=188)$

\begin{tabular}{|l|c|c|}
\hline & Complete posterior circulation & Incomplete posterior circulation \\
\hline Complete anterior circle & $16(8.5 \%)$ & $67(36 \%)$ \\
\hline Incomplete anterior circle & $10(6 \%)$ & $95(50.5 \%)$ \\
\hline
\end{tabular}

The p-value is .054402.

Table 7 shows that association between integrity of anterior and posterior circle was not statistically significant.

The mean diameters of ACA was $-2.3 \mathrm{~mm}$, PCA was $-2.4 \mathrm{~mm}$, ACOM was - 1.3 and PCOM was 1.8 .

Fetal type configuration was noted in $22 \%$ of individuals. Unilateral fetal type circulation noted in $19 \%$ of individuals $(n=188)$ out of which $47 \%$ having pure and 53\%having partial fetal type circulation $(n=36)$. 
Table 8: Contingency table for average vessel diameters in male and female variation

\begin{tabular}{|l|c|c|c|c|c|}
\hline & ACA & ACOM & RPCOM & LPCOM & PCA \\
\hline $\begin{array}{l}\text { MALE } \\
(\mathbf{n = 1 1 3})\end{array}$ & 2.4 & 1.38 & 1.79 & 1.86 & 2.46 \\
\hline $\begin{array}{l}\text { FEMALE } \\
\text { (n=75) }\end{array}$ & 2.3 & 1.21 & 1.77 & 1.79 & 2.36 \\
\hline P value & 0.250 & 0.043 & 0.854 & 0.514 & 0.263 \\
\hline
\end{tabular}

Table 9: Average vessel diameters in below and above 60 yrs age group (in mm)

\begin{tabular}{|l|c|c|c|c|}
\hline Age Groups & ACA & PCA & ACOM & PCOM \\
\hline$<$ 60 yrs & 2.43 & 2.40 & 1.33 & 1.73 \\
\hline$>$ 60 yrs & 2.24 & 2.44 & 1.29 & 1.83 \\
\hline P value & 0.024 & 0.701 & 0.657 & 0.312 \\
\hline
\end{tabular}

In the present study the MRA resolution ratio was about $0.5 \mathrm{~mm}$ and the artery vessels with diameters over $0.5 \mathrm{~mm}$ could be displayed by MIP method or volume reconstruction.

\section{Discussion}

Knowledge of variations in circle of Willis in entirety is important in present scenario due to several reasons:

1. Predisposition to ischemic stroke: Variation patterns in circle of Willis affect the flow rates significantly as reported by Guangyuzhu et $\mathrm{al}^{2}$. The configuration of contralateral A1 absence with severe stenosis in unilateral ICA presents the highest risk of ischemic stroke. Michael Wholey et al concluded a statistically significant association between stroke \& absent/hypoplastic A1/A2 and PCOM (especially bilateral PCOM) ${ }^{3}$.

2. Complex stroke presentations: It can help explain complex stroke presentations in bilateral cerebral territories which may mimic cord lesions specially in trauma patients.

3. Aneurysm formation: Incidence of aneurysm is higher in population having variant anatomy of circle of Willis including hypoplastic and absent arteries due to increased hemodynamic stress on vessel wall. Perlmutter and Rhoton stated that asymmetry of the anterior circle of Willis results in local alterations in intravascular hemodynamics, may be responsible for the development of aneurysms ${ }^{4}$.Tarulli $\mathrm{E}$ et al concluded that anterior cerebral artery trunk-dominant flow contributes to aneurysm formation, growth,

and instability after coiling treatment ${ }^{5}$. As mentioned by Montake et al, aneurysms occurred always on the thicker side of the ICA-PCOM junction in the case of asymmetrical PCOM, whereas no such difference was noted in the case of asymmetrical ACA in this study ${ }^{6}$. Kayembe et al in his study established a statistically significant correlation between variant Circle of Willis anatomy and aneurysm formation ${ }^{7}$.

4. In vascular surgeries and interventional procedures: Knowledge of variations in circle of Willis prior to surgery may help decide upon the type of cerebral protection measure to be taken for example in a person with incomplete circle of Willis deep hypothermic circulatory arrest rather than selective cerebral perfusion may be safer to prevent post-operative strokes/cerebral ischemia $^{8}$. Similar is the importance of mapping completeness of circle of Willis during carotid endarterectomy. R. Montisci et al concluded that statistically significant association exists between configuration of Circle of Willis (two or more agenesiae/ obstructions) and intolerance to cross clamping ${ }^{9}$.

5. Impact on stroke therapy: The quality of collateral circulation affects the severity and prognosis of stroke patients. Henderson and Eliasziw discovered that the incidence of hemispheric cerebral infarction or transient cerebral ischemic attack was significantly reduced during the perioperative or long-term 
follow-up period for patients with $>70 \%$ stenosis of the internal carotid artery if the normal constituent vessels of the circle of Willis were present ${ }^{10}$.

In addition, a study by Brett Cucchiara et al revealed an association between incomplete circle of Willis and migraine with aura ${ }^{11}$.

Concerning the pathological function of the COW for providing effective collateral perfusion, Chuanyaqiu et al suggested that when the diameters of the vessels constituting the COW were less than $0.5 \mathrm{~mm}$, the vessels can be regarded as absence ${ }^{12}$. Therefore, the MRA morphology of COW can reflect effectively the physiological cerebral perfusion. Other studies have suggested that circle of Willis $<1 \mathrm{~mm}$ cannot provide adequate collateral pathway in case of acute ICA obstruction $^{8,13}$. In our study also, we made these assumptions and classify adequacy of circle of Willis accordingly.

Several studies have documented variations of circle of Willis segmentally but only few studies investigate the variations of $\mathrm{CoW}$ as a whole including simultaneous presence of anterior and posterior circulation variations $8,13,14,15,16,17$. This is especially important since the variations of $\mathrm{CoW}$ usually affect more than one segment of the circle. In this study we have also documented the variations segmentally as well as in entirety.

CoW was complete in $9 \%$ of individuals. Incidence of incomplete $\mathrm{CoW}$ was much higher (91\%) than complete circle. These results are concordant with studies done by Chuanya Qui et al $(7.5 \%)^{12}$, Pradhan et al $(7.9 \%)^{18}$, Bahaddur et al $(16.6 \%)^{19}$, Kondori et al $(20.9 \%)^{20}$, Biswajeet et al $(20 \%)^{21}$.High incidence of complete circle was noted in study by Maaly et $\mathrm{al}^{22}$ and Parthsarthy et al $(\sim 46 \%)^{23}$. It was most likely due to lowering the criteria of hypoplastic vessels. In our study we used it as $1 \mathrm{~mm}$ while in these studies it was $0.8 \mathrm{~mm}$ which results in higher number of completeness. Also, we considered hypoplastic vessel as absent whereas in these studies it was considered in complete circle.
Posterior circle variations were significantly higher than anterior circle $(\mathrm{p}<.00001)$. These results are concordant with studies done by Bahadur et al $\quad(77.3 \%$ complete anterior circulation) $^{19}$, Chuyanaqiu (56\% complete anterior circulation, $10 \%$ complete posterior circulation) $)^{12}$, However, percentage of incomplete circle of Willis was higher in our study compared to studies done by Parthsarthy et al $(70 \%$ anterior circulation complete $40 \%$ posterior circulation

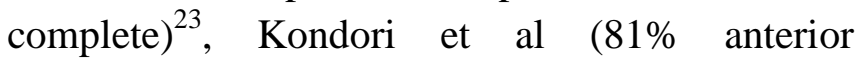
circulation complete, $21 \%$ posterior circulation

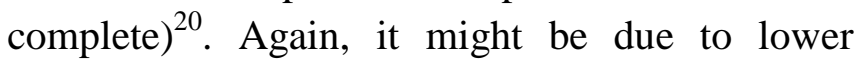
criteria of hypoplastic vessel as $0.8 \mathrm{~mm}$ and considering hypoplastic vessels in complete circle. No significant difference is noted in circle of Willis configuration in male and female populationsimilar to the study by Kondori et $\mathrm{al}^{20} \&$ Chen et $\mathrm{al}^{24}$.

A1 segment of ACA was normal in most of the individuals ( $95 \%)$. The variations in A1 segment in rest of subjects were differently distributed on the left and right side with apparently higher degree on the right side. Laterality in variation of posterior circulation was not present. Consequently, a codominant type anterior circulation was noted in most of the subjects (89\%). A left dominant anterior circulation was noted in $7 \%$ of individuals while right dominant anterior circulation in $4 \%$ indicating a dominant positionof left development. This kind of situation may be related to right handedness with a dominant and superior position on left cerebral hemisphere. The results were similar to the study by Chuanya Qiu et $\mathrm{al}^{12}$.

Most common configuration in anterior circulation was classic complete type (47\%) and rarest being type 3; hypoplastic unilateral A1 with patent contral ateral A1 \& ACOM noted in $3 \%$ of subjects. Most common variation in anterior circulation was hypoplastic/ aplastic ACOM (42\%). Most common posterior circulation configuration was type D; absent bilateral PCOM in $43 \%$. Most frequent association of anterior and posterior circle configuration was type D (absent 
b/l PCOM) with type 1 i.e. classical complete anterior circle in $\sim 50 \%$ of subjects. These findings are similar to Chuanya Qui et al ${ }^{12}$, Parthsarthy et $\mathrm{al}^{23}$, Ayse Karatas et $\mathrm{al}^{25}$ and Yeniceri et $\mathrm{al}^{26}$.

Circle of Willis was classified in entirety as proposed by Papantchev et al $^{8}$.Our results were comparable to their study in which type Ia variation (hypoplastic of either left PCOM or both PCOM) was most common followed by type II b variation(hypoplastic right VA or P1 segment of left PCA) in circle of Willis. In our study, type Ib (hypoplastic ACOM.) variation was comparatively more frequently found than study by Papantchev et al, however Chuanya Qiu et al reported similar incidence of type Ib variation as in our study. Type IV variation was the rarest similar to the study by Papantchev et al. This was most likely due to less number of studied subjects (99) by Papantchev et al.

Vertebral artery hypoplasia was not related to laterality and there is almost similar number of hypoplastic vessels on right as well as left (8\%). Also, no statistically significant correlation noted between vertebral artery hypoplasia and hypoplastic/absent P1 segment. In our study, the overall frequency of vertebral artery hypoplasia was $16.5 \%$. These results are in concordance with Jeng et al $\{11.6 \%$ (7.8\% on the right and $3.8 \%$ on the left) $\}^{27}$.

9\% individuals had a complete COW. $36 \%$ had complete anterior circle and incomplete posterior circle. 5\% had incomplete anterior circle and complete posterior circle. $50 \%$ had incomplete anterior and posterior circle. These results are in concordance with Chuanya Qiu et al $(6.3 \%$ complete anterior posterior, $41.5 \%$ incomplete anterior incomplete posterior) ${ }^{12}$.

Fetal type configuration noted in $22 \%$ of individuals. In patients in whom p1 segment is either smaller than PCOM or absent and in whom PCOM is present, such people have relatively higher incidence of incomplete anterior circle. Above findings are in concordance with study done by Chuanya Qui et $\mathrm{al}^{12}$, Yeniceri et $\mathrm{al}^{26}$, Gunnal et $\mathrm{al}^{28}$, Ayase Kartas et $\mathrm{al}^{25} \&$ Nordon DG et $\mathrm{al}^{29}(18-23 \%)$.

\section{Comparative study for vessels diameters in male and female population}

\begin{tabular}{|l|c|c|c|c|c|c|c|c|}
\hline \multirow{2}{*}{ Author and year } & \multicolumn{2}{|c|}{ ACA } & \multicolumn{2}{c|}{ PCA } & \multicolumn{2}{c|}{ ACOM } & \multicolumn{2}{c|}{ PCOM } \\
\cline { 2 - 9 } & M & F & M & F & M & F & M & F \\
\hline $\begin{array}{l}\text { Krabbe-HartKamp MJ et al (1998) By } \\
\text { MR Angiography method 30 }\end{array}$ & 1.95 & 1.95 & 1.9 & 1.75 & 1.2 & 1.1 & 1.1 & 1.15 \\
\hline $\begin{array}{l}\text { HSIN-WEN CHEN et al (2004) By 3D- } \\
\text { TOF-MRA 24 }\end{array}$ & 2.0 & 2.0 & 1.8 & 1.85 & - & - & - & - \\
\hline Maaly M et al (2011)22 & 1.99 & 1.92 & 1.89 & 1.79 & 1.18 & 1.12 & 1.17 & 1.23 \\
\hline $\begin{array}{l}\text { Stefani MA et al (2013) By MR } \\
\text { Angiography31 }\end{array}$ & 2.2 & 2 & 2.3 & 1.9 & - & - & - & - \\
\hline Present study & 2.4 & 2.3 & 2.5 & 2.4 & 1.4 & 1.2 & 1.83 & 1.79 \\
\hline
\end{tabular}

The mean diameters of vessels were found to be slightly greater in males as compared to females. Mean vessel diameters of vessels of posterior circulation was higher in our study as compared to previous studies. It might be due to higher incidence of incomplete posterior circulation in our study. Rest of the results were comparable to other studies as mentioned above.

Average vessel diameters are observed to be greater in anterior circle in below 60age group and in above 60 age group posterior circle diameters are larger. However, statistically significant difference exists only in ACA which is larger in less than $60 \mathrm{yr}$ age group.

In the present study the MRA resolution ratio was about $0.5 \mathrm{~mm}$ which is better than most of previous studies due to slice thickness of $0 \mathrm{~mm}$ and increased matrix size.

There seems to be no difference between races in the anatomic variation patterns of circle of Willis as studied in Chinese, Egyptian, Brazilian, Russian or Indian population ${ }^{3,12,20,23,32,33,34,35}$.

The present study had some limitations. First, since our study was based on the analysis of MR 
images, description of fine arterial networks could have been missed and was beyond the capability of MR examination. It can be improved by the higher spatial resolution of MRI. Second, most of the subjects were above 60yrs age. Also, number of male subjects was higher which might influence the results.

\section{Conclusion}

This study comprehensively describes variations of circle of Willis including anterior and posterior circle configurations, their correlation with each other, emphasizing their clinical significance and importance of its variations in various neurointerventional procedures. Circle of Willis has great influence on clinical prognosis of cerebrovascular diseases and its anatomy can be accurately assessed using MRA. 3D TOF MRA is a fast, non-invasive \& non-radioactive technique. In today's scenario, the role of 3D TOF MR angiography in preoperative evaluation of patients undergoing brain, ICA \& aortic arch surgeries and advanced interventional procedures cannot be underestimated to avoid life-threatening complications.

\section{Conflicts of interest}

The authors report no conflicts of interest. The authors alone are responsible for the content and writing of this article.

\section{Bibliography}

1. Alnaes MS, Isaksen $\mathrm{J}$, Mardal $\mathrm{K}$ et al. Computation of hemodynamics in the circle ofWillis. Stroke. 2007; 38: 2500-5.

2. Zhu G, Yuan Q, Yang J et al. The role of the circle of Willis in internal carotid artery stenosis and anatomical variations: a computational study based on a patientspecific three-dimensional model; Bio Medical Engineering Online. 2015; Vol 14:107

3. Wholey M, Wu A, Nowak I et al. Early use of multislice CTA to evaluate the distal internal carotid artery and the Circle of Willis and their correlation with stroke. Endovascular Today 2009; 33-44.

4. Perlmutter D, Rhoton A. Microsurgical anatomy of the anterior cerebral - anterior communicating - recurrent artery complex. J Neurosurg. 1976; Vol 45:259-272.

5. E. Tarulli, M. Sneade, A. Clarke et al. Effects of Circle of Willis Anatomic Variations on Angiographic and Clinical Outcomes of Coiled Anterior Communicating Artery Aneurysms. American Journal of Neuroradiology August 2014, Vol 35 (8):1551-1555.

6. Montake K, Hazama F, Handa $\mathrm{H}$ et al. Variation of the circle of Willis related to the pathogenesis of cerebral aneurysm. Neurol Med Chir (Tokyo). 1976; Vol 16:427-435.

7. Kayembe K, Sasahara M, Hazama F. Cerebral Aneurysms and Variations in the Circle of Willis. Stroke. 1984; Vol 15 (5), 846-850.

8. Papantchev V, Todorova D, Paloff A et al. Some variations of the circle of Willis, important for brain protection in cardiac surgery - a new interpretation of the classical work of Adachi: "Anatomie der Japaner. Das Arteriensystem der Japaner”. Praemedicus since 1925. 2006; Vol 27:19.

9. Montisci R, SanfilippoVR, Bura R. et al. Status of the Circle of Willis and Intolerance to Carotid Cross-clamping. European Journal of Vascular and Endovascular Surgery 2013; Vol 45 (2):107-112.

10. Henderson RD, Eliasziw M, Fox AJ et al. Angiographically defined collateral circulation and risk of stroke in patients with severe carotid artery stenosis. North American Symptomatic Carotid Endarterectomy Trial (NASCET) Group. Stroke. 2000; Vol 31(1):128-32.

11. Cucchiara B, Wolf R, Nagae L et al. Migraine with Aura Is Associated with an 
Incomplete Circle of Willis: Results of a Prospective Observational Study. PLoS ONE 2013; Vol 8(7): e71007.

12. ChuanyaQiu, Yong Zhang, CaixiaXue et al. MRA Study on Variation of the Circle of Willis in Healthy Chinese Male Adults. BioMed Research International. 2015; Vol. 2015, Article ID 976340, 8 pages, http://dx.doi.org/10.1155/2015/976340

13. Eftekhar B, Dadmehr M, Ansari S et al. Are the distribution of variations of circle of Willis different in different populations? - Results of an anatomical study and review of literature. BMC Neurol 2006; Vol 6:22. PMC1543654.

14. Riggs HE, Rupp C. Variation in form of circle of Willis. The relation of the variations to collateral circulation: anatomic analysis. Arch Neurol1963;8:8-4.

15. Fisher CM. The circle of Willis: anatomical variations. Vasc Dis 1965;2:99-105.

16. Lazorthes G, Gouaze A, Santini J et al. The arterial circle of thebrain (circulus arteriosus cerebri). AnatClinica 1979;1:241-257.

17. El Khamlichi A, Azouzi M, Bellakhdar F et al. Anatomic configuration of the circle of Willis in the adult studied by injectiontechnics. Apropos of 100 brains. Neurochirurgie 1985;31:287-93.

18. Pradhan P, Baral K, Dan U et al. Morphological study of circle of Willis- A short review. Journal of Anatomical Society of India. 2009; Vol 58 (1):3 5-39.

19. Bahaddur A, Chandan G. Anatomical Variants of Circle of Willisin South Indian Population: A Study by Using Magnetic Resonance Angiography. International Journal of Science and Research 2015; Vol 4 (5):1077-1080.

20. Kondori BJ, Azemati F, Dadseresht S. Magnetic Resonance Angiographic Study of Anatomic Variations of the Circle of
Willis in a Population in Tehran. Arch Iran Med. 2017; 20(4):235 -239.

21. Saikia B, Handique A, Phukan P et al. Circle of willis: variant forms and their embryology using gross dissection and magnetic resonance angiography. Int $\mathrm{J}$ Anat Res 2014;2(2):344-53.

22. Maaly MA, Ismail AA. The Egyptian Journal of Radiology and Nuclear Medicine 2011; Vol 42:405-412.

23. Parthasarthy A, Shatagar S. Anatomical variations in circle of Willis in a random study group. International Journal of Recent Trends in Science and Technology. 2016; 20(1): 140-145.

24. Chen HW, Yen PS, Lee CC et al. Magnetic Resonance Angiographic Evaluation of Circle of Willis in General Population: A Morphologic Study in 507 Cases. Chin J Radiol 2004; 29: 223-229.

25. Karatas A, Coban G, Cinar C et al. Assessment of the Circle of Willis with Cranial Tomography Angiography. Medical Science Monitor: International Medical Journal of Experimental and Clinical Research. 2015; 21:2647-2652.

26. Yeniçeri I, Çullu N, Deveer M et al. Circle of Willis variations and artery diameter measurements in the Turkish population. Folia Morphol (Warsz). 2017; 76(3):420425.

27. Jeng J S, Yip P K. Evaluation of vertebral artery hypoplasia and asymmetry by colorcoded duplex ultrasonography. Ultrasound in Med Biol. 2004; Vol 30(5) 605-609.

28. Gunnal S, Farooqui M, Wabale R, Anatomical Variations of the Circulus Arteriosus in Cadaveric Human Brains. Neurology Research International 2014, Article ID 687281, 16 pages, 2014. doi:10.1155/2014/687281.

29. Nordon, D, Rodrigues O. Variations in the brain circulation - the circle of Willis.J. Morphol. Sci., 2012; 29(4): 243-47. 
30. Hartkamp K, Grond J, Leeuw FE. et al. Circle of Willis: Morphologic variation on three dimensional Time-of-flight MR Angiogram. Radiology. 1998; Vol 207(1) :103-111.

31. Stefani M, Schneider F, Marrone A et al. Influence of the Gender on Cerebral Vascular Diameters Observed during the Magnetic Resonance Angiographic Examination of Willis Circle. Braz. Arch. Biol. Technol. 2013; Vol 56 (1):45-52.

32. Harizi E, Rroji A, Gabrani S. Anatomical Variations of The Circle Of Willis In Adult Human Brains: A Case-Control Study In Albania. Management in health Research 2014; Vol 18 (4):33-35.

33. Zulu H, BuumbaPN, Silitongo $M$ et al. Anatomical Variations of the Circle of Willis as seen at the University Teaching Hospital, Lusaka, Zambia. Journal of Preventive and Rehabilitative Medicine 2016, Vol. 1(2):61-66.

34. Naveen S, Bhat V, Karthik G. Magnetic resonance angiographic evaluation of circle of Willis: A morphologic study in a tertiary hospital set up. Ann Indian Acad Neurol 2015; Vol 18:391-397.

35. Macchi C, Lova RM, Miniati B et al. The Circle of Willis in healthy older persons. $\mathrm{J}$ Cardiovasc Surg (Torino) 2002, Vol 43: 887-890. 